\title{
Correlatos psicosociales de la adhesión al tratamiento antirretroviral en el Centro Penitenciario de hombres de Barcelona
}

\author{
Herraiz $F^{*}$, Villamarín $F^{* *}$, Chamarro $A^{* *}$
}

Centro Penitenciario de Hombres de Barcelona.

Universidad Autónoma de Barcelona.

Universidad Autónoma de Barcelona.

\section{RESUMEN}

Objetivo: Evaluar la adhesión terapéutica al TARGA de los pacientes reclusos con VIH y su relación con diferentes tipos de variables. Material y Método: Estudio longitudinal, realizado en el Centro Penitenciario de Hombres de Barcelona. Se utilizaron las bases de datos del centro, una entrevista semiestructurada, que valoraba variables sociodemográficas, penales/penitenciarias, clínicas y características del tratamiento, así como cuestionarios sobre creencias y estados emocionales. También se evaluó la adhesión al inicio del estudio, a los tres y a los seis meses.

Resultados: Los internos presentaron un bajo apoyo social; un acuerdo medio respecto de los cuidados recibidos por el personal médico y sanitario; consideraron la complejidad del tratamiento como alta y concedieron una moderada relevancia a los efectos secundarios; presentaron un elevado acuerdo respecto a los beneficios que les podían reportar seguir el tratamiento, una percepción moderada sobre la severidad de la enfermedad y manifestaron una elevada autoeficacia en el seguimiento del tratamiento. Respecto a las variables emocionales mostraron una baja tensión, depresión, cólera y fatiga. La adhesión a los antirretrovirales desde el inicio al final del estudio no ha variado a lo largo del estudio. Las variables socio-cognitivas que correlacionaron con la adhesión en los diferentes momentos del estudio son la autoeficacia, los beneficios percibidos, la complejidad del tratamiento y los efectos secundarios. Los estados emocionales que correlacionaban con la adhesión eran la depresión y la fatiga. Discusión: La relación entre autoeficacia y adhesión es un resultado repetido en los estudios sobre la predicción de la adhesión al TARGA. Las relaciones de la fatiga y de la tristeza/depresión con la adhesión son del tipo esperado.

Palabras clave: Adhesión. TARGA. Variables psicosociales. Prisión

\section{PSYCHOSOCIAL CORRELATES OF THE ADHERENCE TO ANTIRRETROVIRAL TREATMENT OF MEN IN PENITENTIARY CENTER OF BARCELONA}

\begin{abstract}
Objective: to assess therapeutic adherence to HAART amongst HIV positive inmates and its likely relationship with sets of different variables.

Materials and Methods: longitudinal study carried out at the Men's Prison of Barcelona (Centro Penitenciario de Hombres de Barcelona). The prison data base, a semi-structured interview assessing socio-penal, demographic and clinical variables as well as treatment characteristics, and questionnaires on beliefs and emotional states were used. Adherence at the beginning of the study, and then after three and six months was also assessed.

Results: inmates presented with low levels of social support, and showed moderate agreement regarding care received from medical and health personnel. They considered the level of treatment complexity to be high and gave moderate relevance to treatment side effects. They presented high agreement with the potential benefits of continuing with the treatment and showed moderate perception of the severity of the illness. They also showed high levels of self efficacy where treatment monitoring was concerned. The emotional variables showed low blood pressure, depression, anger and fatigue. Adherence
\end{abstract}


to antiretroviral treatment did not vary throughout the study period. Socio-cognitive variables that correlated with adherence at different times of the study were self efficacy, perceived benefits, treatment complexity and side effects. Emotional states that correlated with adherence were depression and fatigue.

Discussion: the relationship between self efficacy and adherence is frequently mentioned in studies on the prediction of HAART adherence. The relationship between the two factors of fatigue and sadness/depression and adherence was expected.

Key words: Patients dropouts; HAART; epidemiological facors; prisons.

Texto recibido: Febrero 2008

Texto aceptado: Septiembre 2008

\section{INTRODUCCION}

Desde la aparición de los primeros casos de SIDA en el año 1981 hasta la actualidad, se han producido aproximadamente 25 millones de muertes a causa de la infección por el Virus de Inmunodeficiencia Adquirida (VIH), y se calcula que, en la actualidad, hay unos 40 millones de personas infectadas por el VIH.

A partir de la aparición del TARGA (Tratamiento Antirretroviral de Gran Actividad) se ha reducido considerablemente la morbilidad de pacientes con $\mathrm{VIH}$, convirtiéndose en una enfermedad crónica. Para la obtención de un beneficio terapéutico en el tratamiento antirretroviral, objetivizado en la consecución de una carga viral indetectable en el período más corto de tiempo, se requiere de un cumplimiento estricto de aquél. La falta de adhesión al tratamiento antirretroviral facilita la emergencia de mutaciones resistentes a los fármacos y la aparición de resistencias cruzadas entre los fármacos, lo cual supone una disminución en el arsenal de terapéuticas disponibles y una dificultad para encontrar terapias farmacológicas alternativas eficaces. Además, a nivel socio-familiar, implica un coste económico muy importante, un aumento del absentismo laboral y un enorme coste familiar, por el sobreesfuerzo que supone el cuidado de los pacientes.

La prevalencia de infección por VIH entre los reclusos en las cárceles españolas es la más alta de Europa, situándose entre un 15,1 y un 20\% según diferentes estudios ${ }^{1-4}$.

Laliga ${ }^{5}$, señala que, en la comunidad autónoma de Cataluña en octubre de 2004, sobre una población penitenciaria de 7.978 reclusos, los equipos sanitarios habían estudiado a 6.535 personas $(81,91 \%)$, y del porcentaje analizado, un total de $1.484(22,71 \%)$ se encontraron infectados por el VIH.

En el ámbito penitenciario se han realizado escasos estudios sobre la adhesión al TARGA y en la mayoría se han utilizado variables sociodemográficas y relacionales como posibles correlatos de la adhesión terapéutica y, solo en una minoría variables de carácter sociocognitivo (riesgo percibido, eficacia percibida del tratamiento, etc.). Además, todas las investigaciones que incluían variables psicológicas eran estudios transversales y, por tanto, no consideraban los posibles cambios a través del tiempo.

El objetivo del presente estudio es evaluar la adhesión terapéutica al TARGA de este tipo de paciente y evaluar su relación con diferentes tipos de variables agrupadas en estas categorías: sociodemográficas, penales/penitenciarias, clínicas, características del tratamiento y psicológicas (relacionales, sociocognitivas y emocionales).

\section{MATERIAL Y METODOS}

De los 163 internos VIH positivos en tratamiento con antirretrovirales que de media estaban ingresados en el Centro Penitenciario de Hombres de Barcelona, se seleccionó una muestra de conveniencia de 79 internos, que fuera probable que permanecieran en el centro más de seis meses y que estuvieran ubicados en todas las galerías del centro. Todos ellos aceptaron participar voluntariamente tras explicarles los objetivos del estudio. Cada uno de los internos seleccionados fue entrevistado individualmente por el primer autor en una entrevista inicial y en dos de seguimiento, a los tres y a los seis meses. La recogida datos se inició en octubre de 2003 y finalizó en enero de 2005.

A los tres meses, la muestra había descendido a 57 internos y a los seis meses de seguimiento a 41 internos.

Se midieron las siguientes variables:

Sociodemográficas: Edad, estado civil y nivel de estudios. Los valores fueron extraídos del expediente del interno. La utilización del código de identificación permitía mantener el anonimato. 
Situación penal/penitenciaria: Situación penal, duración condena, actividades desarrolladas, adaptación a la normativa regimental, régimen de vida y tipología delictiva. Los valores penales/penitenciarios fueron extraídos del expediente del interno.

Variables clínicas: Diagnóstico VIH, la vía de transmisión, el estado virológico e inmunológico (mediante el recuento de CD4 y la carga viral), el estadio de la enfermedad, así como la presencia de trastornos psiquiátricos y problemática de drogas. El recuento de las células CD4 se recodificó en: menos de 200 CD4, entre 200 y 350 CD4 y más de 350 CD4. La carga viral se recodificó en: indetectable (menor de 50), inferior a 50.000 y superior a 50.000. Los datos se extrajeron de la base de datos del programa sanitario del centro.

Características del tratamiento antirretroviral: Número de pastillas, tomas, naive/no naive, efectos secundarios y otras medicaciones prescritas. Los datos se extrajeron de la base de datos del servicio de farmacia.

Psicológicas: Se evaluaron la relación médico paciente y las creencias acerca de la enfermedad y el tratamiento. Para esto último, utilizamos una adaptación del Adherence Determinants Questionnaire $(\mathrm{ADQ})^{6}$ que mide el apoyo social, los cuidados recibidos por el personal sanitario, los beneficios percibidos del tratamiento, la percepción de severidad, la percepción de existencia de barreras para seguir el tratamiento y las creencias normativas. Del cuestionario de Shively, Smith, Bormann y Gifford ${ }^{7}$ extrajimos ítems para medir la capacidad para el manejo de la medicación (autoeficacia 1) así como la capacidad para comunicarse con los profesionales sanitarios (autoeficacia 2). Los estados de ánimo se evaluaron mediante la forma B de la adaptación castellana del Profile of Mood States (POMS) ${ }^{8}$. Para todas estas variables se adoptó una escala de respuesta tipo Lickert de 5 puntos.

Adherencia: utilizamos un autoinforme del grado de adhesión global (AD1), en el cual se pedía al paciente que calificara su grado de adhesión a los antirretrovirales en cuatro categorías: "muy buena" (95$100 \%)$, "buena” (90-95\%), “aceptable" (80-90\%) y "baja" (inferior al $80 \%$ ) y un segundo autoinforme de adhesión (AD2) relativo al número de las pastillas no ingeridas en los últimos cuatro días. Posteriormente, se calculó para cada paciente un índice de adhesión consistente en el número de pastillas tomadas en los últimos cuatro días, dividido por el número de pastillas prescritas en estos cuatro días, multiplicado por cien. Este índice nos permitiría clasificar a los pacientes que presentaban una adhesión superior al $95 \%$, como adherentes respecto de los pacientes que presentaron una adhesión menor. Estos últimos fueron clasificados como no adherentes.

Para el análisis de datos se calcularon estadísticos descriptivos de todas las variables. Para los análisis bivariados se utilizó la prueba de chi-cuadrado para las variables cualitativas. Para el grado de relación de utilizó el coeficiente de correlación de Pearson. Para todos los análisis de utilizó el paquete estadístico SPSS 12.0 en castellano.

\section{RESULTADOS}

En la tabla I se presentan las características de la muestra al inicio del estudio. La edad media era de 36,4 años, el 61,3\% estaban solteros. El 1,3\% eran analfabetos, un 34,75 cursaba estudios primarios, un $42,7 \%$ cursaba estudios de secundaria y un $1,3 \%$ cursaba acceso a la universidad. El 86,7\% estaba condenado, siendo el robo $(66,2 \%)$ y los delitos contra la salud pública $(10,8 \%)$ los motivos de ingreso más frecuentes. Un $94,7 \%$ eran reincidentes, un $97,3 \%$ cumplían condena en régimen ordinario y el $44 \%$ participaban en las actividades del centro.

Respecto a las características clínicas y del tratamiento (ver tabla 2), el 73,4\% de los internos habían contraído el VIH a través del intercambio de jeringuillas, siendo usuarios de drogas por vía parenteral. Un $66,7 \%$ no tenían el SIDA. El tiempo medio transcurrido desde el diagnóstico de la infección por VIH hasta el momento de la entrevista se situó en 149 meses. La mayoría de internos habían tenido experiencias previas en la ingesta de antirretrovirales. Como razones para la interrupción o cambio de tratamiento los internos adujeron como motivos fundamentales los efectos secundarios (40\%), descenso CD4 $(9,2 \%)$, sentirse enfermo $(9,2 \%)$ y complejidad del tratamiento $(7,7 \%)$, principalmente $\left(\chi^{2}=79,76\right.$ (9); $\mathrm{p}=0,000)$. El nivel basal medio de CD4 al inicio del estudio era de 346.17 (DS=205.40). La carga viral media era 17.911 (DS=33.831) y el $50 \%$ de los internos de la muestra mostraban una carga viral indetectable. En cuanto al número de pastillas ingeridas, la media se situó en 4,67, y su rango varió entre una y trece pastillas diarias. Además de antirretrovirales, consumían fármacos de carácter general y psicotrópicos.

Los internos referían sufrir efectos secundarios o 
molestias, en los últimos 3-6 meses, destacaron: hormigueo en manos y pies $(37,3 \%)$, dolor de cabeza $(16 \%)$, nauseas y vómitos $(9,3 \%)$, sensación de cansancio $(9,3 \%)$ y piel seca $(4 \%)\left(\chi^{2}=134,88(13)\right.$; $\mathrm{p}=0,000)$. En relación con el motivo por el cual no habían ingerido alguna dosis de la medicación antirretroviral, los internos informaron como principal motivo el olvido. Con menor frecuencia aparecieron otros motivos, como los efectos secundarios, quedarse dormido, sentirse nervioso o deprimido, haber agotado la medicación o no llevar la medicación consigo. No se apreciaron diferencias estadísticamente significativas respecto a los motivos de no ingesta de las dosis $\left(\chi^{2}=8,15(4) ; \mathrm{p}=0,086\right)$.

\section{Nivel cultural}

Primer nivel instrumental (analfabeto)

$1(1,3 \%)$

Segundo nivel instrumental (neolector)

$11(14,7 \%)$

Tercer nivel instrumental (certificado)

Primer nivel graduado (secundaria primer grado)

Segundo nivel post-graduado (secundaria segundo grado)

Acceso mayores 25 años

$15(20 \%)$

$32(42,7 \%)$

$15(20 \%)$

$1(1,3 \%)$

Estado civil

Soltero

Casado/pareja

Divorciado/separado

$46(61,3 \%)$

$15(20 \%)$

$14(18,7 \%)$

\section{Actividades en el centro}

$\mathrm{Si}$

$33(44 \%)$

No

$42(56 \%)$

Situación penal

Penados

$65(86,7 \%)$

Preventivos

Penado + preventiva

$8(10,7 \%)$

$2(2,6 \%)$

Reincidencia penitenciaria

Si

$71(94,7 \%)$

No

$4(5,3 \%)$

Régimen de vida

Ordinario (Segundo grado)

Cerrado (Primer grado)

$73(97,3 \%)$

$2(2,7 \%)$

Tipología delictiva principal

Robo

$49(66,2 \%)$

Contra la salud pública

$8(10,8 \%)$

Homicidio

$5(6,8 \%)$

$4(5,4 \%)$

$4(5,4 \%)$

Lesiones

$4(5.4 \%)$

Otros (Hurto, violencia doméstica, falsificación...)
Media (DS)

$36,4(5,31)$

Edad (años)

$1948(1766,38)$

Condena (días)

$2,25(2,51)$

Tabla I. Características socio-demográficas y penales-penitenciarias de la muestra al inicio del estudio 
Vía de transmisión

Contacto heterosexual

Usuario de drogas por vía parenteral

$15(23,4 \%)$

No sabe

$47(73,4 \%)$

$2(3,2 \%)$

Estado enfermedad

Sida

$24(32 \%)$

No Sida

Tratamiento previo

Si (no naive)

$57(79,2 \%)$

No (naive)

Razones interrupción/cambio de tratamiento antirretroviral

Efectos secundarios medicación

$26(40 \%)$

No mejora

$1(1,5 \%)$

Complejidad tratamiento

$5(7,7 \%)$

Descenso CD4

$6(9,2 \%)$

Recaída en el consumo de drogas

$3(4,6 \%)$

Depresión

Enfermedad

Aumento de carga viral

$2(3,1 \%)$

Olvido

$6(9,2 \%)$

$3(4,6 \%)$

Otros

$1(1,5 \%)$

$12(18,6 \%)$

Ingesta otro tipo de medicación

Psicotrópicos

$28(49,1 \%)$

General

$16(28,1 \%)$

Psicotrópicos + general

$13(22,8 \%)$

Tiempo transcurrido desde el diagnóstico (meses)

Media (DS)

$149(66,07)$

$\mathrm{N}^{\circ}$ de pastillas de antirretrovirales prescritas al día

$4,67(2,67)$

Variables psicosociales

Apoyo social

Cuidados personal médico y sanitario

Barreras percibidas para seguir el tratamiento

$5,07(3,32)$

$5,15(1,87)$

$2,16(1,06)$

Beneficios del tratamiento

Severidad enfermedad

$14,58(3,81)$

$2,04(1,11)$

$4,60(2,44)$

$7,16(1,92)$

$6,51(2,52)$

Autoeficacia manejo medicación

$107,88(9,69)$ 


\begin{tabular}{|c|c|c|c|c|c|c|}
\hline \multirow{2}{*}{$\begin{array}{l}\text { Variables independientes } \\
\text { Variables sociocognitivas }\end{array}$} & \multicolumn{3}{|c|}{ AD1 } & \multicolumn{3}{|c|}{ AD2 } \\
\hline & $\mathbf{r}$ & Signif. & $\mathbf{N}$ & $\mathbf{r}$ & Signif. & $\mathbf{N}$ \\
\hline Línea base & \multicolumn{6}{|c|}{ LÍNEA BASE } \\
\hline Subescala Autoeficacia 1 & 3,381 & ,001 & 74 &,- 385 & 001 & 74 \\
\hline Subescala severidad & ,177 & 135 & 73 &,- 243 & 038 & 73 \\
\hline Subescala percepción beneficios &, 438 &, 000 & 71 &,- 318 &, 007 & 71 \\
\hline Subescala de complejidad percib. &, 479 &, 000 & 74 &,- 493 &, 000 & 74 \\
\hline Subescala de efectos secundarios &, 149 & 206 & 74 &,- 416 &, 000 & 74 \\
\hline Linea base & \multicolumn{6}{|c|}{ TRES MESES } \\
\hline Subescala de complejidad percib. &,- 553 &, 000 & 56 & ,372 &, 005 & 55 \\
\hline Subescala de efectos secundarios &,- 068 & 620 & 56 & 276 & 039 & 55 \\
\hline Linea base & \multicolumn{6}{|c|}{ SEIS MESES } \\
\hline Subescala Autoeficacia 1 & 379 & 016 & 41 &,- 377 & ,014 & 40 \\
\hline Subescala percepción beneficios &, 330 & 043 & 40 &,- 150 & ,367 & 38 \\
\hline Tres meses & & & SEI & SES & & \\
\hline Subescala Autoeficacia 1 & 403 & 020 & 34 & 035 & 844 & 33 \\
\hline \multicolumn{7}{|l|}{ Variables del estado de ánimo } \\
\hline Linea base & \multicolumn{6}{|c|}{ SEIS MESES } \\
\hline Vigor &,- 265 & 098 & 40 & ,378 & ,014 & 41 \\
\hline Depresión &,- 082 & ,613 & 40 & 374 & ,015 & 41 \\
\hline Tres meses & & & SEI & SES & & \\
\hline Fátiga &,- 528 & 001 & 39 & ,377 & ,015 & 41 \\
\hline Vigor &, 425 &, 007 & 39 &,- 324 & 039 & 41 \\
\hline \multicolumn{7}{|l|}{ Variables de la enfermedad } \\
\hline Linea base & \multicolumn{6}{|c|}{ SEIS MESES } \\
\hline Células CD4 &,- 016 & ,925 & 39 &,- 365 & 019 & 41 \\
\hline Tres meses & \multicolumn{6}{|c|}{ SEIS MESES } \\
\hline Células CD4 & 041 & 807 & 37 &,- 390 & 014 & 39 \\
\hline Carga Viral &, 418 & 017 & 32 & 311 & ,074 & 34 \\
\hline
\end{tabular}

* Indicadores de adhesión: AD1: Autoinforme del grado de adhesión global; AD2: Autoinforme de adhesión respecto a las pastillas no ingeridas en los últimos cuatro días.

Tabla III. Correlaciones significativas de las variables psicológicas y de la enfermedad con los indicadores de adhesión al tratamiento a lo largo del estudio.

Respecto a la relación con los sanitarios, un $60 \%$ consideraba haber recibido poca ayuda por parte de los servicios médicos. Dos tercios de los participantes manifestaron que recientemente (entre los últimos 3 ó 6 meses) habían mantenido alguna entrevista con los servicios médicos para tratar cuestiones relacionadas con el VIH/SIDA y un $41,5 \%$ las habían evaluado de forma no satisfactoria. Otro dato a destacar es que un $56 \%$ habían recibido la visita del mismo profesional, mientras que el resto afirma- ba que les habían visitado profesionales diferentes. Casi la mitad de los internos $(44,7 \%)$ se encontraban insatisfechos por la corta duración de la entrevista.

En cuanto al tratamiento de la drogodependencia, la mayor parte de la muestra presentaba una historia de consumo de drogas. Al inicio del estudio, un 49\% de los internos informaron de consumos recientes de haschís, un 30\% de opiáceos, un $18 \%$ de ansiolíticos y un $12 \%$ de cocaína. Un $56 \%$ de la muestra se en- 
contraba en tratamiento de drogas en el programa de mantenimiento con metadona.

Respecto a las creencias sobre la enfermedad y el tratamiento, destaca que los internos consideran tener un bajo apoyo social para el seguimiento del tratamiento, exceptuando el proporcionado por el personal sanitario del centro. A este respecto, mostraron un acuerdo medio respecto de los cuidados recibidos por el personal médico y sanitario. La complejidad del tratamiento era considerada alta, mientras que los efectos secundarios eran considerados moderados. Presentaban un elevado acuerdo respecto a los beneficios y la conveniencia de seguir el tratamiento, una percepción moderada sobre la severidad de la enfermedad y manifestaron tener una alta capacidad de tomar toda la medicación siguiendo la prescripción establecida y para comunicarse de forma eficiente con el personal sanitario del centro. Respecto a su estado de ánimo, los internos mostraron una baja tensión, depresión, cólera, fatiga y vigor.

El nivel de adhesión $\mathrm{AD} 1$, valorado por medio del grado de adhesión informado por los internos como "muy bueno" fue de un $68,05 \%$ al inicio del estudio. Por otra parte, el indicador de adhesión AD2, indica que el 68,4\% de los internos mostraban una adhesión superior o igual al $95 \%$. Los dos indicadores de adhesión correlacionaban entre ellos $(r=-0,51$; $\mathrm{p}=0,001)$.

El grado de adhesión estimado registró oscilaciones durante los seis meses de seguimiento, como muestra la figura 1 . Así respecto a la adhesión estimada por los pacientes al inicio del estudio un $72 \%$ de los internos informaron de un grado de adhesión superior o igual al $95 \%$; a los tres meses este porcentaje de buenos cumplidores fue del $68 \%$ y a los seis meses del $77 \%$. La adhesión calculada a partir del número de pastillas también experimentó oscilaciones, tal como indica la figura 2, así un $77 \%$ de los pacientes cumplieron el criterio de buenos cumplidores al inicio del estudio, un $82 \%$ a los tres meses y un $77 \%$ a los seis meses. Estas oscilaciones en el porcentaje de buenos cumplidores no se mostraron estadísticamente significativas (valores de los estadísticos; $\mathrm{p}=0,56 \mathrm{y}$ $\mathrm{p}=0,59$ para ambos indicadores respectivamente).

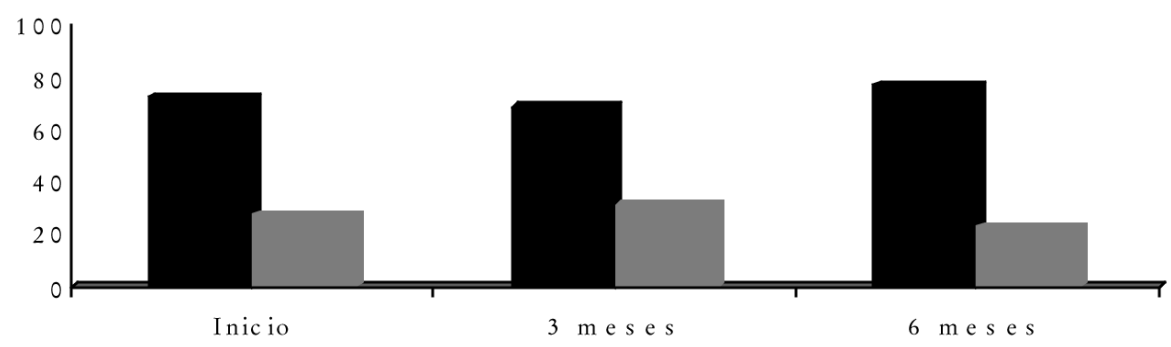

Internos adherentes al TARGA (>95\%) Inte rnos no a dhe re ntes al TARGA $(<95 \%)$

Figura 1. Adhesión de los internos al TARGA a partir de la adhesión autoinformada.

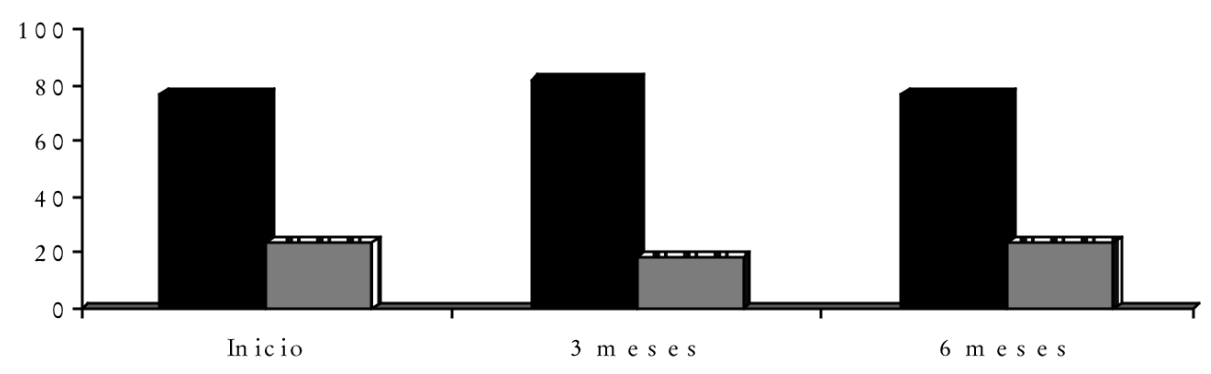

Internos Adhe rentes al TARGA (> 95\%) $\square$ Internos no adherentes al TARGA $(<95 \%)$

Figura 2. Adhesión de los internos al TARGA a partir de las pastillas no ingeridas en los últimos cuatro días. 
Como puede observarse en la tabla III las variables sociocognitivas, emocionales y las relacionadas con la enfermedad muestran diferentes grados de relación con la adhesión a lo largo del estudio. Así, al inicio, la autoeficacia general $(r=0,311 ; p=0,007)$, la autoeficacia sobre el manejo de la medicación $(\mathrm{r}=0,381 ; \mathrm{p}=0,001)$, la percepción de beneficios $(r=0,438 ; p=0,000)$, y la percepción de complejidad del tratamiento $(r=0,479 ; p=0,000)$, muestran correlación con el grado de adhesión autoinformado. Si la adhesión se valora en términos de número de pastillas no ingeridas, las variables que correlacionan son las mismas, junto a la percepción de severidad $(\mathrm{r}=-0,243 ; \mathrm{p}=0,038)$ y los efectos secundarios $(\mathrm{r}=-0,416 ; \mathrm{p}=0,001)$.

En cambio, la adhesión autoinformada a los tres meses de iniciar el tratamiento sólo muestra correlación con la percepción de complejidad de tratamiento $(r=-0,553 ; p=0,000)$. Si la adhesión se valora en términos de número de pastillas no ingeridas, se observa correlación con la percepción de complejidad de tratamiento $(r=0,372 ; p=0,005)$ y con los efectos secundarios $(r=0,276 ; p=0,039)$. A los seis meses, sin embargo, son la autoeficacia general $(r=0,403 ; p=0,010)$ y para el manejo de la medicación $(r=0,379 ; p=0,016)$, junto con la percepción de beneficios $(r=0,330 ; p=0,043)$ los que muestran algún grado de correlación con el grado de adhesión autoinformada. Para el número de pastillas no ingeridas, los que muestran relación son la autoeficacia para el manejo de la medicación, el vigor físico $(\mathrm{r}=0,378 ; \mathrm{p}=0,014)$, el ánimo depresivo $(\mathrm{r}=0,374 ; \mathrm{p}=0,015)$ y el número de CD4 $(\mathrm{r}=-0,365$; $\mathrm{p}=0,019)$.

Si se considera la relación entre la etapa intermedia (tres meses) y el final del estudio, es la autoeficacia general $(r=0,356 ; p=0,046)$ y para el manejo de la medicación $(\mathrm{r}=0,403 ; \mathrm{p}=0,020)$, junto con la fatiga $(r=-0,528 ; \mathrm{p}=0,001)$ el vigor $(\mathrm{r}=0,427$; $\mathrm{p}=0,007)$ y la carga viral $(\mathrm{r}=0,418 ; \mathrm{p}=0,017)$ los que muestran relación con el grado de adhesión autoinformada. Respecto al número de pastillas no ingeridas, este indicador de adhesión correlaciona con la fatiga $(r=0,377 ; p=0,015)$, el vigor $(r=-0,324$; $\mathrm{p}=0,039)$ y el recuento de CD4 $(\mathrm{r}=-0,39 ; \mathrm{p}=0,014)$.

\section{DISCUSION}

Los datos referidos a las variables sociodemográficas y penales-penitenciarias de los sujetos de nuestro estudio, así como los relativos a la principal vía de infección y al consumo de sustancias, son simila- res a los aportados por otras investigaciones con población reclusa, tanto realizadas en nuestro país ${ }^{1,10-}$ ${ }^{14}$ como los llevados a cabo en el ámbito anglosajón ${ }^{15-17}$. No encontramos ninguna relación significativa entre las variables sociodemográficas y los indicadores de adhesión. Estos resultados son coherentes con los encontrados en los estudios revisados por Ammassari et a ${ }^{18}$.

En el momento de inicio del estudio el tratamiento antirretroviral comportaba un promedio de 4,7 pastillas totales diarias. Consideramos interesante comentar que la complejidad objetiva del TARGA, definida como número de pastillas diarias, ha disminuido enormemente, si las comparamos con la de los primeros años en que se puso en marcha este tratamiento (en torno a veinte pastillas diarias).

Respecto a la relación con los profesionales sanitarios, nuestros datos indican una falta de continuidad en la atención, siendo ésta una de las variables de carácter organizativo-estructural que más perjudica la adhesión terapéutica en los tratamientos y en nuestro estudio de adhesión al TARGA ${ }^{15}$.

El porcentaje de reclusos no adherentes al tratamiento antirretroviral, considerando como tales a aquellos con una tasa de adhesión menor del $95 \%$, se situó al inicio del estudio entre un $23 \%$ y un $28 \%$, según consideremos el indicador "número de pastillas no ingeridas" o el indicador "adhesión estimada”. La proporción de no adherentes aportada por los estudios con población reclusa, oscila entre un mínimo del $16 \%{ }^{15}$ y un máximo del $54,8 \%{ }^{1}$, pasando por valores como el $24 \%{ }^{14}$, el $25 \%{ }^{10}$ el $38 \%{ }^{16}$ el $50 \%{ }^{12}$ y el $54 \%{ }^{13}$. El porcentaje de no adherentes al tratamiento antirretroviral en el ámbito sanitario (hospitalario ambulatorio) oscila en un intervalo del $38 \%$ al $58 \%{ }^{19}$. El índice ligeramente superior de adhesión en los reclusos tratados con antirretrovirales podría deberse, en parte, a la dispensación semanal de la medicación, procedimiento que implica en principio una supervisión más estricta del tratamiento que la que se realiza habitualmente en el ámbito sanitario.

En el transcurso del estudio hemos encontrado que las oscilaciones en el porcentaje de buenos cumplidores no se mostraron estadísticamente significativos a lo largo de los tres momentos de evaluación. De todos modos, y aún en el caso de que el porcentaje de buenos cumplidores hubiera sido aritméticamente el mismo en los tres momentos de evaluación, estos resultados no nos dicen nada sobre si los sujetos "buenos cumplidores" son exactamente los mismos en las diferentes evaluaciones. Lo que no cambia de forma significativa es el porcentaje global de 
buenos cumplidores, pero los pacientes incluidos en esta categoría pueden variar de una evaluación a otra. Esto iría en la línea de la idea apuntada, entre otros, por Fogarty y otros ${ }^{20}$ de que la adhesión no es un constructo estable, sino un proceso que puede variar a lo largo del tiempo.

Del conjunto de variables sociocognitivas, las que correlacionaron significativamente con la adhesión son la autoeficacia, los beneficios percibidos (a mayor autoeficacia y mayores beneficios anticipados, mejor adhesión), la complejidad percibida (a mayor complejidad percibida, peor adhesión) y el ítem relativo a los efectos secundarios. Estas correlaciones se encontraron en diferentes momentos.

La relación entre autoeficacia y adhesión es un resultado repetido en los estudios sobre la predicción de la adhesión al TARGA ${ }^{18,19}$. Queremos destacar que de las dos medidas de autoeficacia (capacidad para el manejo de la medicación y capacidad para la comunicación con el personal sanitario) la que más se relaciona con la adhesión es la primera. Por lo tanto, parece aparecer una relación positiva entre los beneficios anticipados y la adhesión. La complejidad percibida mostró una relación inversa con la adhesión y, hasta cierto punto, podría considerarse, una medida "anverso" de la autoeficacia, medida que algunos autores han denominado "esfuerzo percibido" 19 .

Por lo que respecta a las variables emocionales, se encontraron correlaciones significativas entre los estados de ánimos: fatiga, depresión/tristeza y vigor con los indicadores de adhesión al TARGA. Las relaciones de la fatiga y de la tristeza/depresión con la adhesión son del tipo esperado: a mayor fatiga y mayor tristeza/depresión, peor adhesión. Las correlaciones del vigor con la adhesión son contradictorias.

Nuestro estudio presenta algunas limitaciones como la pérdida progresiva de participantes, que coincide con lo ocurrido en otro estudio de carácter multicéntrico realizado en Cataluña ${ }^{11}$ la utilización de dos indicadores únicos, que aunque se han mostrado eficaces, sería conveniente complementarlos con otras medidas y, finalmente, que todos los reclusos participantes eran varones y pertenecían a un solo centro penitenciario, lo que conlleva limitaciones en la generalización de los resultados.

De cara al futuro creemos conveniente la realización de más estudios de carácter longitudinal, de carácter multicéntrico, en que se utilicen pacientes reclusos varones y mujeres, en que se preste especial atención a las variables psicológicas.

\section{CORRESPONDENCIA}

F. Herraiz.

Centro Penitenciario de Hombres de Barcelona.

c/ Entença, 155

Barcelona

Correo electrónico: FELIXH8@terra.es

\section{REFERENCIAS BIBLIOGRÁFICAS}

1. Blanco JM, Pérez IR, De Labry Lima AO, Recio JM, López EG, Lasanta JJ. Adherence to antiretroviral treatment in prisons. AIDS Res Hum Retroviruses. 2005; Aug, 21 (8): 683-8.

2. Sáiz de la Hoya P, Bedia M, Murcia J, Cebriá J, Sánchez-Payá J, Portilla J. Factores predictivos de infección por el VIH, VHC y coinfección en la población reclusa de una prisión española. Enf Infecc Microbiol Clin 2005; 23: 53-7.

3. Encuesta estatal sobre salud y drogas entre los internados en prisión. (ESDIP) 2006. Dirección General de Atención a las Drogodependencias.

4. Olry de Labry A, Plazaola J, Ruiz I, Soto JM, Antón JJ, Castro JM, Girela E. Estado clínico y psicosocial de reclusos en tratamiento con antirretrovirales. Rev Esp Sanid Penit. 2003; 5: 92-100.

5. Laliga A. Particularidades de la atención sanitaria de personas afectadas por el VIH en el medio penitenciario catalán. AIDS Cyber J [serial online] 2005, 8 (2) [Citado 1 Sept 2005]; 8. Disponible en: URL:http://www.ttmed.com/spain/texto_art_lon g.cfm?ID_cou=20EID_Art=1317EID_Secc=1EI D_dis=31EID_TA=2

6. DiMatteo MR, Hays RD, Gritz ER, Bastani R, Crane L, Elashoff R, et al. Patient adherence to Cancer Control Regimens; Scale Development and Initial Validation. Psychol Assess. 1993; 5 (1): 102-112.

7. Shively M, Smith TL, Bormann J, Gifford AL. Evaluating Self-efficacy for HIV diseases Management Skills. AIDS behav. 2002; 6 (4): 371-379.

8. McNair DM, Lorr M, Droppleman LF. Profile of Mood States Manual. San Diego, C.A: Educational and Industrial Testing Services. 1971. Adaptación de Fuentes I, García-Merita M, Melià JL, Balaguer I. (1994). Forma abreviada del Perfil de los Estados de ánimo (POMS). Actas del V Congreso Nacional de Psicología de la Actividad Física y del Deporte, Valencia: Universitat de València; 1994: 29-39.

9. Frontier Science Foundation. ACTG Adherence follow-up Questionnaire [En línea]. 2005. [Cita- 
do 15 febrero 2005]; Disponible en URL: https:// www.fstrf.org/qol/aactg/q10702_spa.pdf

10. Gallego C, Marco A, Da Silva A, Varouche C, Argüelles, MJ, Monfort A, et al. Causas de abandono del tratamiento antirretroviral (TARV) y eficacia de la entrevista motivacional en la mejora de la adherencia. Rev Esp Sanid Penit 2004; 6 (1): 2-7.

11. Marco A, Gallego C, Lonca M, Pérez-Amigó P, Monfort A, Gramunt J, et al. Estudio multicéntrico penitenciario sobre adherencia a corto plazo de una pauta antirretroviral con Nelfinavir y/o Saquinavir. Rev Esp Sanid Penit. 2002; 4: 4-9.

12. Marco A, Martín V, Garrote G. Sida y población reclusa en España. Jano. 1996; 50: 996-1002.

13. Olry de Labry A, Plazaola J, Ruiz I, Soto JM, Antón JJ, Castro JM, et al. Estado clínico y psicosocial de reclusos en tratamiento con antirretrovirales. Rev Esp Sanid Penit. 2003; 5: 92-100.

14. Soto JM, Pérez IR, March JC. Adherence to antiretroviral therapy among HIV-infected prison inmates. Int J STD AIDS. 2005; 16 (2): 133-138.

15. Altice FL, Mostashari F, Friedland GH. Trust and acceptance of and adherence to antiretroviral therapy. J Acquir Immune Defic Syndr. 2001 Sep 1; 28 (1): 47-58.
16. Mostashari F, Riley E, Selwyn PA, Altice, FL. Acceptance and adherence with antiretroviral therapy among HIV-infected women in a correctional facility. J Acquir Immune Syndr Hum Retrovirol. 1998 Aug 1; 18 (4): 341-8.

17. Wohl DA, Stephenson BL, Golin CE, Kiziah CN, Rosen D, Ngo B, et al. Adherence to directly observed antiretroviral therapy among human immunodeficiency virus-infected prison inmates. Clin Infect Dis. 2003 Jun 15; 36 (12): 1572-6.

18. Ammassari A, Trotta MP, Murri R, Castelli F, Narciso P, Noto P, et al. Correlates and predictors of adherence to highly active antiretroviral therapy: overview of published literature. J. Acquir Immune Defic Syndr. 2002 Dec 15; 31 Suppl 3: S123-7.

19. Tuldrà A. Adhesió terapéutica al tractament antiretroviral. [Tesis doctoral]. Bellaterra: Univ. Autónoma de Barcelona; 2005.

20. Fogarty L, Rotter D, Larson S, Burke J, Gillespie J, Levy R. Patient adherence to HIV medication regimens: a review of published and abstract reports. Patient Educ Couns. 2002 Feb; 46 (2): 93108. 